Fr equent det ect i on of mul t i drug-resi st ant pneumoni a causi ng bacteri a i $n$ the pneumoni a I ung ti ssues of pat i ent s wi th hemat ol ogi cal mal i gnanci es

\begin{tabular}{|l|l|}
\hline 著者 & $\begin{array}{l}\text { I NAl Kuni hi r o, I WASAK H rom chi, NORI K } \\
\text { Sakon, I KEGAYA Sat oshi, YAMASH TA Nasanor i , } \\
\text { I NAMURA Yoshi aki, TAK MOTO Nobuo, KATO } \\
\text { H sat aka, UEDA Takanor i, NAI W H r onobu }\end{array}$ \\
\hline $\begin{array}{l}\text { j our nal or } \\
\text { publ i cat i on t i t l e }\end{array}$ & I nt er nat i onal j our nal of hemat ol ogy \\
\hline vol une & 86 \\
\hline number & 3 \\
\hline page $r$ ange & $225-232$ \\
\hline year & $2007-10$ \\
\hline URL & ht t p: //hdl . handl e. net /10098/1812 \\
\hline
\end{tabular}




\section{Frequent Detection of Multi-drug Resistant Pneumonia-causing Bacteria in the Lung Tissues of Patients with Hematological Malignancies}

Kunihiro Inai ${ }^{1^{*}}$, Hiromichi Iwasaki ${ }^{2}$, Sakon Noriki ${ }^{3}$, Satoshi Ikegaya ${ }^{1}$, Masanori Yamashita $^{4}$, Yoshiaki Imamura ${ }^{5}$, Nobuo Takimoto ${ }^{1}$, Hisataka Kato ${ }^{3}$, Takanori Ueda ${ }^{2}$, Hironobu Naiki ${ }^{1}$

${ }^{1}$ Division of Molecular Pathology, ${ }^{2}$ Division of Hematology and Cardiology, ${ }^{3}$ Division of Tumor Pathology, ${ }^{4}$ Division of Clinical Inspection, and ${ }^{5}$ Diagnostic Pathology Division, University of Fukui, Faculty of Medical Sciences, Fukui, Japan.

Running title: Agonal pneumonia in hematological patients

* To whom correspondence should be addressed: Kunihiro Inai, MD, PhD Address: 23-3 Matsuoka-Shimoaizuki, Eiheiji, Fukui 910-1193, Japan Phone \& Fax: +81-776-61-8123

E-mail: kinai@u-fukui.ac.jp 


\section{Abstract}

Pneumonia is a critical issue during the agonal phase, and often becomes lethal in the absence of pathogen detection. Autopsy is a powerful tool for analyzing the cause of a patient's death, progression of the disease, and the therapeutic response. However, it is frequently limited to the identification of bacterial strains. To elucidate the pathogenesis during the agonal phase of pneumonia, intrapulmonary sputum was harvested by directly inserting a swab into a resected lung, and the bacterial composition was analyzed using both pathological and microbiological techniques from 15 patients with hematological malignancies, and the results were compared with those from 25 patients with other medical and surgical diseases. Among the 54 bacteria strains isolated from the 40 patients, multi-drug resistant strains were significantly more prevalent in hematological group than in other diseases (16/21 vs. 11/33, $\mathrm{p}=0.002)$. Enterococcus faecium was preferentially isolated from the hematological patients, whereas the methicillin-resistant Staphylococcus aureus was predominantly found in the non-hematological group. Two coagulase-negative Staphylococcus epidermidis strains in hematological diseases may be diagnosed as causative bacteria of pneumonia by both bacterial and pathological techniques. Although the results of this study may not be directly applicable for clinical diagnosis, this approach has a potential to become not only a diagnostic method for bacterial pneumonia, but may be also useful for the analysis of multi-drug resistant pathogens. 
Main category: (C) Hematological malignancies

Subcategory: (E-3) Infection, (C-6) Hematological malignancies-others

Key words: autopsy, hematological malignancy, intrapulmonary sputum, multi-drug resistant bacteria, pathology, pneumonia 


\section{Introduction}

The number of pathogens resistant to commonly used antibiotics has been increasing in both the general population and nosocomial infections [1-3]. In hospitals, widespread use of antibiotics, increased numbers of immunocompromised hosts, and introduction of new antibiotics have led to the development of multi-drug resistant strains [4]. Therefore, early testing for drug resistant strains is important for successful anti-microbial treatment [2, 5]. However, in immunocompromised patients, including those with leukemia, lymphoma, or HIV, the infectious disease usually shows rapid progression, and the overall prognosis is very poor. Consequently, it is rare for physicians to identify the causative bacterial species or assess the therapeutic effect of antibiotics against the pathogen.

Performing an autopsy can help establish the cause of a patient's death in relation to the systemic progression. However, identification of the precise microbial strains has limitations, especially in cases of opportunistic bacterial infections. To address this problem, we investigated the bacterial composition of pneumonia at autopsy using both pathological and microbiological techniques in patients with hematological malignancies. Moreover, we compared the prevalence of drug-resistant microbial flora with that of other medical or surgical diseases. In this paper, we report that we could effectively identify pathogens including multi-drug resistant bacteria, fungi, and viruses in the pneumonia lung tissues of patients with hematological disease 
in the life-threatening phase by a combination of microbiological and pathological methods. Although the results of this study may not be applicable for clinical diagnosis, the accumulation of these basic data will contribute to the clinical managements of pneumonia in hematological malignancies.

\section{Materials and Methods}

Patients, autopsy, and the collection of intrapulmonary sputum.

Forty cadavers ranging from 23 to 90 years old (median, 69) at the time of death who underwent autopsy at the University of Fukui Hospital were enrolled in this study. Written informed consent was obtained from the families of each patient. Profiles of the study cohort are described in Table 1 . Of the 40 patients, 15 suffered from hematological malignancies and the remaining 25 patients comprised of 17 malignant tumors and 8 benign diseases.

Intrapulmonary sputum was collected as follows (Figure 1). After removing the ribs and heart, the pulmonary hilum was clamped and the trachea and vessels were interrupted by a scalpel. Then, intrabronchial expectoration was collected by directly inserting a sterile swab into the bronchi. Samples were harvested from the lung according to the following criteria: (i) when a lesion was apparent during the lifetime, sputum was obtained from the side of the lesion, or (ii) if the degree of pneumonia was evaluated equally in each lung, the lung with the heavier weight was decided to be the 
candidate for sputum collection.

Bacterial culture and antimicrobial sensitivity test.

To isolate the bacterial strain in the lung, the samples were inoculated onto mannitol salt agar, egg salt agar, and blood agar. Following incubation for $48 \mathrm{~h}$ at $37^{\circ} \mathrm{C}$, identification of the presumptive colonies and an antimicrobial susceptibility test were performed using a MicroScanWalkAway apparatus (DADE Behring) according to the criteria of the Clinical and Laboratory Standards Institute (CLSI) [6, 7]. Minimum inhibitory concentrations (MICs) for antibiotics were determined using CLSI broth microdilution panels.

Antimicrobial susceptibility testing using the scoring system.

To compare the resistant profiles between the hematological and non-hematological groups, we defined the sensitivity as follows: when an antimicrobial drug test resulted in sensitivity, intermediate sensitivity, or resistance against a pathogen, the drug was given $+1,0$, or -1 point, respectively. An estimated total amount $<0$ was assumed to indicate a multi-drug resistant bacterium.

Statistical analysis.

Statistical analysis was performed using the $\chi^{2}$ test, Fisher's exact probability 
test, or Student's $t$-test. A p value less than 0.05 was considered to be significant.

\section{Results}

Isolated bacteria from patients with hematological diseases had a tendency to be more resistant than those with non-hematological diseases.

Isolated microorganisms and prescribed antimicrobial agents are listed in Table 2. Thirty-seven out of the 40 autopsied patients had more than one bacterial species. Overuse of antimicrobial agents contributes to the spread of resistance determinants. Since patients with hematological diseases tended to be prescribed significantly more antibiotics than patients with other diseases $(5.9 \pm 2.6$ agents vs. $1.5 \pm 1.3$ agents, respectively, $\mathrm{p}=8.6 \times 10^{-9}$ ), we compared the appearance of multi-drug resistant bacteria in the hematological group with that in the non-hematological group using an antimicrobial susceptibility scoring system (Table 3). The percentage of resistant isolates from patients with hematological diseases (16/21) was significantly higher than from those with non-hematological diseases $(11 / 33)(p=0.002)$. In the hematological group, more than 70\% of both Gram-positive and Gram-negative pathogens acquired multiple antimicrobial resistances. In contrast, more than $80 \%$ of the Gram-negative floras in non-hematological diseases still exhibited drug sensitivity $(\mathrm{p}=0.005)$, despite the evolution of antimicrobial drug resistance of Gram-positive floras in this group, as well as the hematological group. 
Antibiotic susceptibility results including the cases of methicillin-resistant Staphylococcus aureus (MRSA) [8, 9], vancomycin-resistant Enterococcus (VRE) [10, 11], and tuberculosis [12, 13] are usually tabulated for large populations of individual isolates, and the data are displayed by every tested antibiotic. On the other hand, antibiotic susceptibility also depends on the immune status or the antibiotic usage of the host. However, few reports mention resistant phenotypes among disorder groups by the number of antibiotics to which the strain is resistant [14]. Therefore, we adopted a comparison between the hematological and non-hematological groups via the resistance rate of a series of susceptibility tests in the isolates (Table 3) using our original index, since there has been no established effective criteria to quantify the seriousness of drug resistance. The mean susceptibility index from all isolates was $-2.4 \pm 4.5$ in the hematological group and $2.8 \pm 5.8$ in the non-hematological group $(\mathrm{p}=0.0015)$. Similarly, Gram-negative floras in the hematological group were more resistant than in the non-hematological group ( $-2.3 \pm 5.0$ vs. $4.2 \pm 3.7, \mathrm{p}=0.0023)$. On the other hand, the index in Gram-positive floras didn’t show significance between the two groups. The degree of resistance in the hematological group was equal when the data were added up according to the Gram-positive organisms (-2.5 \pm 4.4$)$ and Gram-negative bacteria (-2.3 $\pm 5.0)$.

High frequency of morphologically isolated pathogens in hematological diseases. 
Documented microorganisms in lung tissue provide absolute proof of pneumonia. Thus, we evaluated the pathogens in resected lungs to exclude the colonization of bacteria in the trachea according to the criteria in Pathologic Basis of Disease [15], and compared the results in hematological with those in non-hematological diseases. Viral pneumonia was diagnosed according to the existence of pathological pneumonia with: (i) morphologically well-established viral inclusion bodies, (ii) an increased serum level of specific viral antibody, or (iii) specific viral gene amplification by PCR. In 12 hematological patients with pathological pneumonia, the types of pneumonia were 4 bacterial, 3 combined, 3 viral, 1 fungal, and 1 aspiration pneumonia. In contrast, half of the morphological pneumonia in the non-hematological group represented bronchial pneumonia with abscess formation or a significant infiltration of neutrophils and macrophages in the absence of pathogen detection in alveolar spaces (10 in 19 cases). Regarding pathogenic organisms, bacteria were detected in 7 of 12 cases in the hematological group and 4 of 19 cases in the non-hematological group ( $\mathrm{p}=0.035)$, viruses in 4 of 12 versus 0 of $19(\mathrm{p}=0.007)$, and funguses in 3 of 12 versus 2 of 19 ( $p=0.286)$, respectively (Table 4).

Marked prevalence of E. faecium in hematological diseases.

Even though several risk factors for MRSA infection or colonization have been reported [16, 17], few reports have demonstrated leukemia or lymphoma as a risk factor 
of MRSA infection. Indeed, MRSA represented 47\% of all detected Gram-positive organisms derived from the non-hematological group ( $p=0.03$, data not shown), while only one MRSA was isolated from the hematological group. To determine the bacterial strains likely to be concentrated in hematological diseases, the attributes of isolated bacterial floras were evaluated among the two groups. As shown in Figure 2, E. faecium comprised 6 of 14 Gram-positive organisms in the hematological cohort, whereas bacterial flora were not detected in the non-hematological cohort $(\mathrm{p}=0.0027)$. Next, coagulase-negative staphylococcus, primarily methicillin-resistant Staphylococcus epidermidis (MRSE), comprised in 4 of 14 Gram-positive organisms in the hematological group, although the incidence was not significantly different. Interestingly, two patients (Patients 4 and 7 in the hematological group) with MRSE only showed scattered cocci in the lung tissues (Figure 3), suggesting that these patients were infected with MRSE.

In addition, we analyzed the aspects regarding the detection of these two pathogens within 4 weeks before the patients' death (Figure 4). Three of six patients with MRSE at autopsy had undergone bacteria detection 4 weeks previously. Two of the remaining MRSE-positive patients became positive at 1 week before autopsy. $E$. faecium was likely to be identified at a later stage in comparison with MRSE, because three of 5 E. faecium (60\%) cases were first isolated at autopsy. Three of six patients were identified as having both MRSE and E. faecium. 


\section{Discussion}

Autopsy can identify the cause of a patient's death regarding the pathophysiological progression of the disease. However, it is difficult to identify the bacterial strain using morphological analysis only, especially in cases of bacterial pneumonia, because samples taken from the air tract and alimentary canal contain bacterial colonization as well as resident microbiological flora. Colonization without VRE infection was reported to be caused by acute myeloid leukemia and related to a longer stay in hospital [18]. Moreover, the detection rate of bacterial culture was reported to show a dramatic reduction only 25 min after the prescription of an antibiotic [19]. Since patients with hematological malignancies tend to undergo prolonged admission and to antimicrobial overuse, bacterial culture may run the potential risk of misjudgment unless an additional method of verification is performed simultaneously. In fact, bacteria could be isolated from 14 out of 15 hematological patients by the microbial technique, while the existence of bacteria in paraffin-embedded sections was limited to 7 of 12 patients with morphologically proven pneumonia in this study. Taken together with these findings, it is suggested that the detection of microorganisms at autopsy in combination with morphological inspection is a valuable and rational tool for the analysis of the pathogenesis of pneumonia.

Increased use of antibiotics has led to the isolation of drug-resistant bacteria [20, 
21]. Similarly, our patients with hematological malignancies were prescribed significantly more types of antimicrobials compared to patients with other diseases (5.9 \pm 2.6 vs. $1.5 \pm 1.3$ antimicrobials, respectively), indicating that our results also support the relation between an increase of drug-resistant bacteria and the heavy use of antibiotics. Not only heavy antimicrobial usage, but also severe underlying diseases and frequent hospitalization have also been described as risk factors for the carriage of drug-resistant organisms [22]. In addition, the bacterial composition detected in patients subtly varies according to facilities, clinical settings, and an individual's background, including basal disease, immune status, or presence of cancer. Therefore, we compared the degree of drug resistance of detected bacteria in each disease group, and found that the antimicrobial resistance rate of all detected pathogens and of Gram-negative floras in the hematological group was significantly higher than that of another cohort. Some investigators tried to define the resistant phenotypes through the number of antibiotics to which the strain was resistant [14]. For physicians, information from the antimicrobial susceptibility test results would not only help evaluate the comprehensive resistance rate of bacteria, but also provide data regarding aging, the immune state, or presence of cancer in every disorder category. In that sense, our retrospective evaluation method of multi-drug resistant microorganisms is thought to help reevaluate antimicrobial treatments over a lifetime.

Our study demonstrated significant accumulations of MRSE and E. faecium in 
hematological patients, and MRSA was predominant in the non-hematological diseases. Coagulase-negative staphylococci, primarily S. epidermidis, have emerged as pathogens in a growing number of nosocomial infections among neonatal, immunocompromised, and catheterized patients [14, 23-25]. However, it is controversial as to whether $S$. epidermidis can evoke infectious diseases such as sepsis and pneumonia, lung failure, or multiple organ dysfunction [26-28]. Indeed, several investigators consider that the strain should be judged to be associated with infectious diseases if it represents the only microorganism isolated from a significant clinical specimen including blood, liquor, purulent exudates, or bronchial fluid [14, 26]. In our data, MRSE or E. faecium was isolated from several patients at autopsy, with E. faecium being particularly likely to be isolated at the point of a patient's death. Thus, these bacteria may be developed as a microbial substitution without documented infectious aspects. On the other hand, the bacterial composition was involved in the pathological lung sections in several patients with the isolates. Because infectious diseases belong to a category in inflammatory disorders, the most striking evidence of documented infection was the development of an acute inflammatory response with infiltration of neutrophils or activated macrophages, fibrin deposition, and focal bleeding in the bacteria-colonized tissues [15]. In this context, our patients were definitely infected with MRSE or E. faecium from the perspective of pathology. Genetic analysis using PCR or DNA microarray analysis of micro-dissected pathological sections would give us useful information regarding the 
existence of pneumonia. In addition, MRSE has another important aspect, being capable of transferring antimicrobial resistance genes to other staphylococci [29, 30]. Therefore, our approach of combined pathological and microbiological methods may be of use to sample resistant bacterial floras and as a method for studying the epidemiological background of pneumonia, especially in the context of pneumonia with hematological diseases.

In conclusion, we found that microorganisms including multi-drug resistant bacteria were recognized at a high frequency in pneumonia lung tissues in the agonal stage of hematological diseases by combining microbiological and pathological methods. Although disease processes are complex and still difficult to clearly understand regarding pneumonia in patients with hematological diseases, our approach has a potential to become not only a diagnostic tool for pneumonia, but also a useful tool for the pathophysiological analysis of pneumonia. 


\section{Acknowledgments}

This research was supported by the Ministry of Education, Science, Sports and Culture, Japan, Grant-in-Aid for K. Inai and H. Naiki. 


\section{References}

[1] Wisplinghoff H, Bischoff T, Tallent SM, Seifert H, Wenzel RP, Edmond MB. Nosocomial bloodstream infections in US hospitals: analysis of 24,179 cases from a prospective nationwide surveillance study. Clin Infect Dis. 2004;39:309-317.

[2] Hoban DJ, Biedenbach DJ, Mutnick AH, Jones RN. Pathogen of occurrence and susceptibility patterns associated with pneumonia in hospitalized patients in North America: results of the SENTRY Antimicrobial Surveillance Study (2000). Diagn Microbiol Infect Dis. 2003;45:279-285.

[3] Jones RN. Resistance patterns among nosocomial pathogens: trends over the past few years. Chest. 2001;119:397S-404S.

[4] File TM, Jr. Overview of resistance in the 1990s. Chest. 1999;115:3S-8S.

[5] Mandell LA, Marrie TJ, Grossman RF, Chow AW, Hyland RH. Canadian guidelines for the initial management of community-acquired pneumonia: an evidence-based update by the Canadian Infectious Diseases Society and the Canadian Thoracic Society. The Canadian Community-Acquired Pneumonia Working Group. Clin Infect Dis. 2000;31:383-421.

[6] National Committee for Clinical Laboratory Standards. Performance standards for antimicrobial disc susceptibility tests; Approved Standard Eighth-edition, M2-A8. Philadelphia; 2003.

[7] National Committee for Clinical Laboratory Standards. Methods for dilution antimicrobial susceptibility tests for bacteria that grow aerobically; Approved Standard Sixth-edition, M7-A6. Philadelphia; 2003.

[8] Haddadin AS, Fappiano SA, Lipsett PA. Methicillin resistant Staphylococcus aureus (MRSA) in the intensive care unit. Postgrad Med J. 2002;78:385-392.

[9] Tan L, Sun X, Zhu X, Zhang Z, Li J, Shu Q. Epidemiology of nosocomial pneumonia in infants after cardiac surgery. Chest. 2004;125:410-417.

[10] Gordon S, Swenson JM, Hill BC, Pigott NE, Facklam RR, Cooksey RC, et al. Antimicrobial susceptibility patterns of common and unusual species of enterococci causing infections in the United States. Enterococcal Study Group. J Clin Microbiol. 1992;30:2373-2378.

[11] Fluit AC, Jones ME, Schmitz FJ, Acar J, Gupta R, Verhoef J. Antimicrobial 
susceptibility and frequency of occurrence of clinical blood isolates in Europe from the SENTRY antimicrobial surveillance program, 1997 and 1998. Clin Infect Dis. 2000;30:454-460.

[12] Zumia A, Grange JM. Multidrug-resistant tuberculosis--can the tide be turned? Lancet Infect Dis. 2001;1:199-202.

[13] Kaufmann SH. How can immunology contribute to the control of tuberculosis? Nat Rev Immunol. 2001;1:20-30.

[14] Villari P, Sarnataro C, Iacuzio L. Molecular epidemiology of Staphylococcus epidermidis in a neonatal intensive care unit over a three-year period. J Clin Microbiol. 2000;38:1740-1746.

[15] Kumar V, Abbas A, Fausto N. Robbins and Cotran pathologic basis of disease. Philadelphia: Elsevier Saunders; 2004.

[16] Maudsley J, Stone SP, Kibbler CC, Iliffe SR, Conaty SJ, Cookson BD, et al. The community prevalence of methicillin-resistant Staphylococcus aureus (MRSA) in older people living in their own homes: implications for treatment, screening and surveillance in the UK. J Hosp Infect. 2004;57:258-262.

[17] Lee NE, Taylor MM, Bancroft E, Ruane PJ, Morgan M, McCoy L, et al. Risk factors for community-associated methicillin-resistant Staphylococcus aureus skin infections among HIV-positive men who have sex with men. Clin Infect Dis. 2005;40:1529-1534.

[18] Timmers GJ, van der Zwet WC, Simoons-Smit IM, Savelkoul PH, Meester HH, Vandenbroucke-Grauls CM, et al. Outbreak of vancomycin-resistant Enterococcus faecium in a haematology unit: risk factor assessment and successful control of the epidemic. Br J Haematol. 2002;116:826-833.

[19] Peters RP, van Agtmael MA, Danner SA, Savelkoul PH, Vandenbroucke-Grauls CM. New developments in the diagnosis of bloodstream infections. Lancet Infect Dis. 2004;4:751-760.

[20] Rahal JJ, Urban C, Segal-Maurer S. Nosocomial antibiotic resistance in multiple gram-negative species: experience at one hospital with squeezing the resistance balloon at multiple sites. Clin Infect Dis. 2002;34:499-503.

[21] Rice LB. Antimicrobial resistance in gram-positive bacteria. American journal of infection control. 2006;34:S11-19; discussion S64-73.

[22] Matar MJ, Tarrand J, Raad I, Rolston KV. Colonization and infection with 
vancomycin-resistant Enterococcus among patients with cancer. American journal of infection control. 2006;34:534-536.

[23] Wade JC, Schimpff SC, Newman KA, Wiernik PH. Staphylococcus epidermidis: an increasing cause of infection in patients with granulocytopenia. Ann Intern Med. 1982;97:503-508.

[24] Horvathova Z, Spanik S, Sufliarsky J, Mardiak J, Pichna P, Pichnova E, et al. Bacteremia due to methicillin-resistant staphylococci occurs more frequently in neutropenic patients who received antimicrobial prophylaxis and is associated with higher mortality in comparison to methicillin-sensitive bacteriemia. Int J Antimicrob Agents. 1998;10:55-58.

[25] Agvald-Ohman C, Lund B, Edlund C. Multiresistant coagulase-negative staphylococci disseminate frequently between intubated patients in a multidisciplinary intensive care unit. Crit Care. 2004;8:R42-47.

[26] Sander A, Beiderlinden M, Schmid EN, Peters J. Clinical experience with quinupristin-dalfopristin as rescue treatment of critically ill patients infected with methicillin-resistant staphylococci. Intensive Care Med. 2002;28:1157-1160.

[27] Dahmash NS, Chowdhury MN, Fayed DF. Coagulase-negative staphylococcal bacteraemia with special reference to septic shock: experience in an intensive care unit. J Infect. 1994;29:295-303.

[28] Bone RC. The pathogenesis of sepsis. Ann Intern Med. 1991;115:457-469.

[29] Miragaia M, Couto I, Pereira SF, Kristinsson KG, Westh H, Jarlov JO, et al. Molecular characterization of methicillin-resistant Staphylococcus epidermidis clones: evidence of geographic dissemination. J Clin Microbiol. 2002;40:430-438.

[30] Wielders CL, Vriens MR, Brisse S, de Graaf-Miltenburg LA, Troelstra A, Fleer A, et al. In-vivo transfer of mecA DNA to Staphylococcus aureus [corrected]. Lancet. 2001;357:1674-1675. 
Table 1. Patient Profiles and Incidence of Detected Pathologic Floras from Resected Lungs at Autopsy.

\begin{tabular}{lcc}
\hline & Hematological Diseases & Non-hematological Diseases* \\
\hline No. of Patients & 15 & $25\left(14^{* *}+11^{* * *}\right)$ \\
Gender (M/F) & $10 / 5$ & $13 / 12$ \\
Age & 60.8 & 67.2 \\
Range & $23-78$ & $42-90$ \\
Median & 64 & 70 \\
\hline
\end{tabular}

*: Non-hematological diseases include patients derived from medical** wards excepting a hematological ward, and surgical*** wards. 
Table 2. Association between Isolated Bacteria and Pathological Findings.

\begin{tabular}{|c|c|c|c|c|}
\hline \multirow[b]{2}{*}{ No. } & \multirow[t]{2}{*}{ Isolated microorganism } & \multicolumn{2}{|c|}{ Pathological findings } & \multirow[t]{2}{*}{ Antimicrobial agents used within two weaks before the patient's death } \\
\hline & & Type & Morphologically isolated organisms & \\
\hline \multicolumn{5}{|c|}{ Hematol } \\
\hline 1 & P. aeruginosa & bacterial & bacteria (rod) & CLDM, CZOP, ISP, MEPH, TEIC, AMPH, LVFX, SPFX, ST \\
\hline 2 & P. aeruginasa & bacterial & bacteria (rod) & ISP, MINO, VCM, AMP, ITCZ \\
\hline 3 & E. faecium & bacterial & bacteria (cocci) & IMP, ISP, SBT/CPZ, ITCZ, SPFX, ST \\
\hline 4 & MRSE, Corynebacterium sp. & bacterial & bacteria (cocci) & IPM, ISP, MEPM, MINO, SBT/CPZ, VCM, AMPH, FLCZ \\
\hline 5 & MRSA, E. faecium, St. maltophilia & combined & bacteria (cocci) + ADV & IPM, ISP, ST \\
\hline 6 & E. faecalis, Al. xylosoxidans & combined & bacteria $($ cocci + rod) + Candida & CZOP, ISP, TEIC, AMPH, ITCZ, SPFX, INH \\
\hline 7 & MRSE, (P. aeruginosa), (Fungus sp.) & combined & bacteria (cocci) + Aspergillus & CZOP, ISP, PIPC, FLCZ \\
\hline 8 & MRSE, E. faecalis, E. faecium, (Candida sp.) & fungal & Aspergillus & CZOP, IMP, ISP, PAPM, ITCZ, LVFX, ST \\
\hline 9 & MRSE, E. faecium, Acinetobacter sp. & viral & $\mathrm{ADV}+\mathrm{CMV}$ & CZOP, ISP, MINO, FLCZ, ITCZ, FLRX, GCV \\
\hline 10 & (MRSE) & viral & CMV & CZOP, ISP, FLCZ, ITCZ, SPFX \\
\hline 11 & & viral & CMV & ISP, MEPM, MINO, PAPM, VCM, AMPH, FLCZ, ITCZ, SPFX, JAN, ST \\
\hline 12 & St. maltophilia & aspiration & & ABPC, CZOP, IMP, VCM, FLCZ, GCV, INH, ST \\
\hline 13 & MRSE, E. faecium & & & ISP, PAPM, FLCZ, ST \\
\hline 14 & E. cloacae, E. faecalis, a-Streptococcus, Neisseria sp. & & & ST \\
\hline 15 & S. simulans, (Candida sp.) & & & AMPH, ITCZ, LVFX, ST \\
\hline \multicolumn{5}{|c|}{ Medical } \\
\hline 1 & K. pneumonia, E. cloacae, C. freundii & bacterial & bacteria (rod) & CLDM, IPM, MINO, VCM \\
\hline 2 & MRSA, K. pneumoniae & bacterial & sepsis (cocci) & \\
\hline 3 & MSSA & bacterial & bacteria (cocci) & \\
\hline 4 & E. faecaris, Candida sp. & fungal & Candida & MEPM \\
\hline 5 & MRSA, E. cloacae., $\alpha$-streptococcus, Neisseria sp. & fungal & Candida & FOM \\
\hline 6 & MRSE, Candida sp., $\alpha$-streptococcus, Neisseria sp. & bronchial & & ABPC, PAPM \\
\hline 7 & MRSA, K. pneumoniae & bronchial & & ISP \\
\hline 8 & MRSA, (Candida sp.) & bronchial & & \\
\hline 9 & Al.xylosoxidans, K. pneumoniae, (Candida sp.) & bronchial & & CLDM, CZOP, FOM \\
\hline 10 & & bronchial & & VCM \\
\hline 11 & (Pseudomonas sp.) & caseous & & MEPM \\
\hline 12 & (MSSA) & & & PAPM \\
\hline 13 & $\alpha$-Streptococcus, $(\gamma$ Streptococcus), (Candida sp.) & & & CPZ, FOM \\
\hline 14 & & & & CPR, LVFX \\
\hline \multicolumn{5}{|c|}{ Surgical } \\
\hline 15 & MRSA & bacterial & bacteria (cocci) & PIPC \\
\hline 16 & MSSA, ( $\alpha$-streptococcus $)$ & bronchial & & PIPC \\
\hline 17 & MRSA, E. faecalis, P. aeruginosa, K. oxytoca & bronchial & & PIPC \\
\hline 18 & MSSA, S. agalactiae, Micrococcus sp. & bronchial & & \\
\hline 19 & MSSA, E. coli, $\alpha$-streptococcus & bronchial & & \\
\hline 20 & P. aeruginosa, E. aerogenes, A. lowffi & bronchial & & IPM \\
\hline 21 & E. faecalis, P. aerginosa & aspiration & & $\mathrm{CZOP}, \mathrm{SBT} / \mathrm{CPZ}$ \\
\hline 22 & MRSA, P. mirabilis & aspiration & & ABK, MINO, FLCZ \\
\hline 23 & MRSA & & & FLCZ, LVFX \\
\hline 24 & $\alpha$-streptococcus, $\gamma$ streptococcus, Neisseria sp. & & & FMOX, PIPC \\
\hline 25 & (P. aeruginosa) & & & FOM, IPM, PIPC, VCM, FLCZ \\
\hline
\end{tabular}

ABK: arbekacin, ABPC: ampicillin, CLDM: clindamycin, CPR: cefpirome, CPZ: cefoperazone, CZOP: cefozopran, FMOX: flomoxef, FOM: fosfomycin, IMP: imipenem, ISP: isepamicin MEPM: meropenem, MINO: minocycline, PAPM: panipenem, PIPC: piperacillin, SBT/CPZ: sulbactam/cefoperazone, TEIC: teicoplanin, VCM: vancomycin,

AMPH: amphotericin B, FLCZ: fluconazole, ITCZ: itraconazole, FLRX: fleroxacin, LVFX: levofloxacin, SPFX: sparfloxacin, GCV: ganciclovir, INH: isonicotinic acid,

JAN: pentamidine, ST: sulfamethoxazole-trimethoprim. ( represents the result of weak positive (1+) flora by bacterial culture. 
Table 3. Resistance Profiles of Antimicrobial Susceptibility Test.

\begin{tabular}{lcc}
\hline & $\begin{array}{c}\text { Resistant } \\
\text { Pathogens }\end{array}$ & $\begin{array}{c}\text { Index of } \\
\text { Susceptibility }\end{array}$ \\
\cline { 2 - 3 } All floras & $16 / 21$ & $-2.4 \pm 4.5(62 \pm 23 \%)$ \\
Hematological & $11 / 33$ & $2.8 \pm 5.8(33 \pm 30 \%)$ \\
Non-hematological & $\mathrm{p}=0.002$ & $\mathrm{p}=0.0015$ \\
& & \\
Gram positive floras & $11 / 14$ & $-2.5 \pm 4.4(63 \pm 22 \%)$ \\
Hematological & $9 / 17$ & $1.6 \pm 7.0(44 \pm 34 \%)$ \\
Non-hematological & $\mathrm{p}=0.14$ & $\mathrm{p}=0.093$ \\
& & \\
Gram negative floras & & \\
Hematological & $5 / 7$ & $-2.3 \pm 5.0(59 \pm 27 \%)$ \\
Non-hematological & $2 / 16$ & $4.2 \pm 3.7(21 \pm 19 \%)$ \\
& $\mathrm{p}=0.005$ & $\mathrm{p}=0.0023$ \\
\hline \multicolumn{2}{c}{ ( ) represents the percentage resistance to tested antibiotics by the } \\
antimicrobial susceptibility test.
\end{tabular}


Table 4. Incidence of Morphologically Isolated Microorganisms.

\begin{tabular}{lccc}
\hline & Hematol & Non-hematol & $p$ value \\
\hline $\begin{array}{l}\text { Detection of } \\
\text { Pathogens }\end{array}$ & $\begin{array}{c}11 / 12 \\
(92 \%)\end{array}$ & $6 / 19$ & 0.0011 \\
Detection of & $7 / 12$ & $4 / 19$ & 0.035 \\
Bacteria & $(58 \%)$ & $(21 \%)$ & \\
Detection of & $4 / 12$ & $0 / 19$ & 0.007 \\
Virus & $(33 \%)$ & $(0 \%)$ & \\
Detection of & $3 / 12$ & $2 / 19$ & 0.286 \\
Fungus & $(25 \%)$ & $(11 \%)$ & \\
\hline
\end{tabular}

Hematol: hematological diseases

Non-hematol: non-hematological diseases 


\section{Legends to Figures.}

Figure 1. Harvesting methods of intrapulmonary sputum at autopsy. After removing the ribs and heart (upper left), the pulmonary hilum was clamped and the trachea and vessels were interrupted by a scalpel (upper right and lower left). Then, intrabronchial expectoration was collected by directly inserting a sterile swab into the bronchi (lower right).

Figure 2. Incidence of E. faecium in Gram-positive bacteria between the hematological and non-hematological groups. The black column represents the isolated number of multi-drug resistant $E$. faecium judged by the antimicrobial susceptibility scoring system.

Figure 3. Documented bacterial growth on a pathological slide isolated from a patient with acute myeloid leukemia. Bacterial cocci were scattered in the lung tissue with focal bleeding. Although MRSE, P. aeruginosa, and fungus sp. were isolated by bacterial culture, MRSE was the only isolated cocci from this patient (Patient No. 7 in the hematological group). Therefore, the patient was diagnosed with MRSE pneumonia.

Figure 4. Isolated profiles of MRSE and E. faecium in hematological patients within 4 
weeks before the patients' death. Bacterial cultures harvested from the throat, sputum, or intrabronchially (at autopsy) were performed at appropriate time points in each patient. Positive detection of MRSE and E. faecium (open circle), or negative results (closed circle) were represented according to the time-course in every patient. 
Figure 1

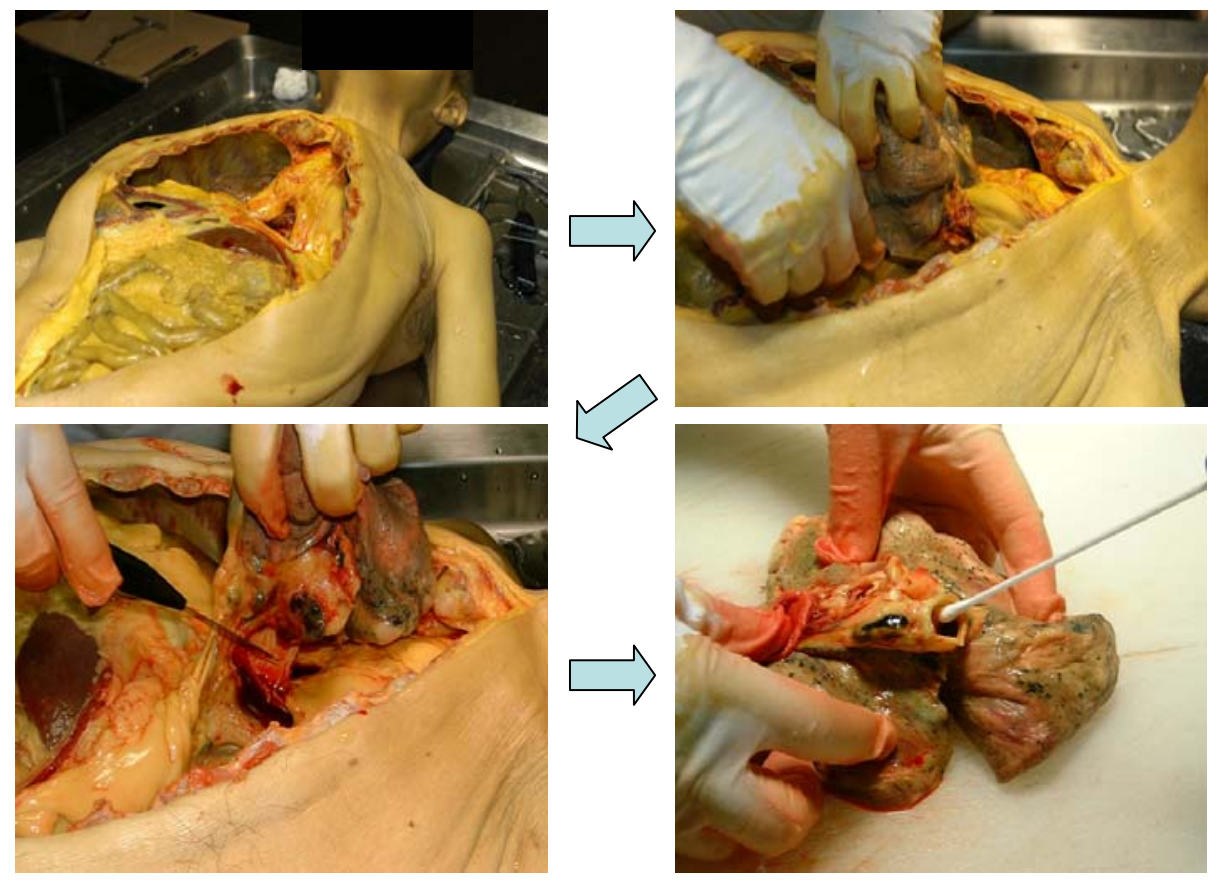


Figure 2

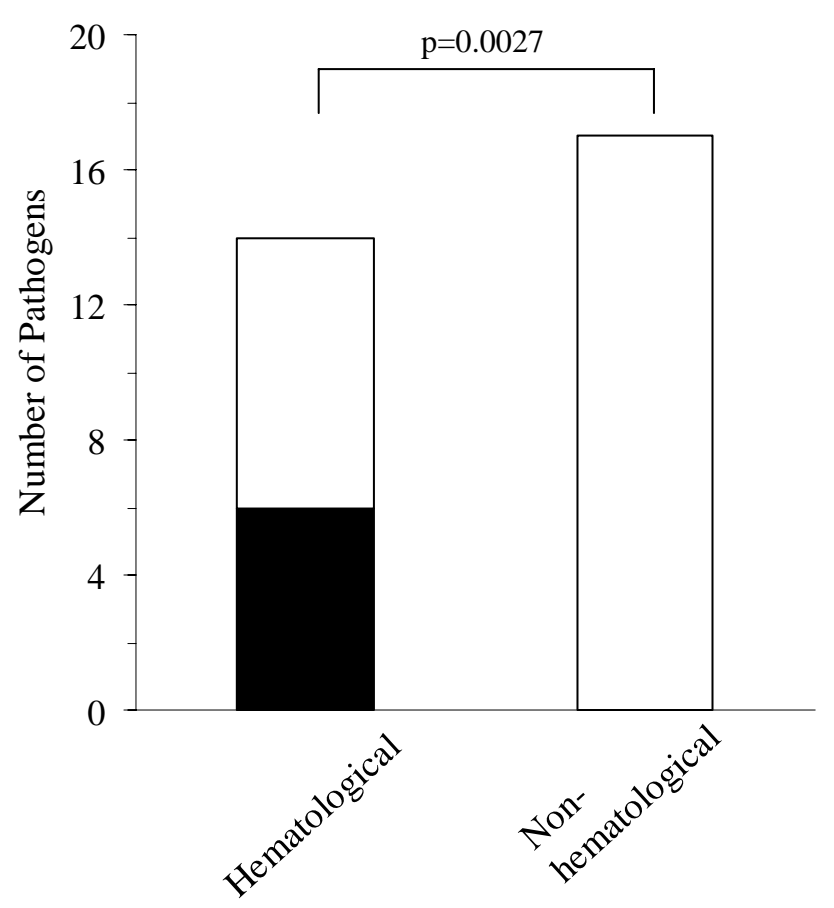


Figure 3

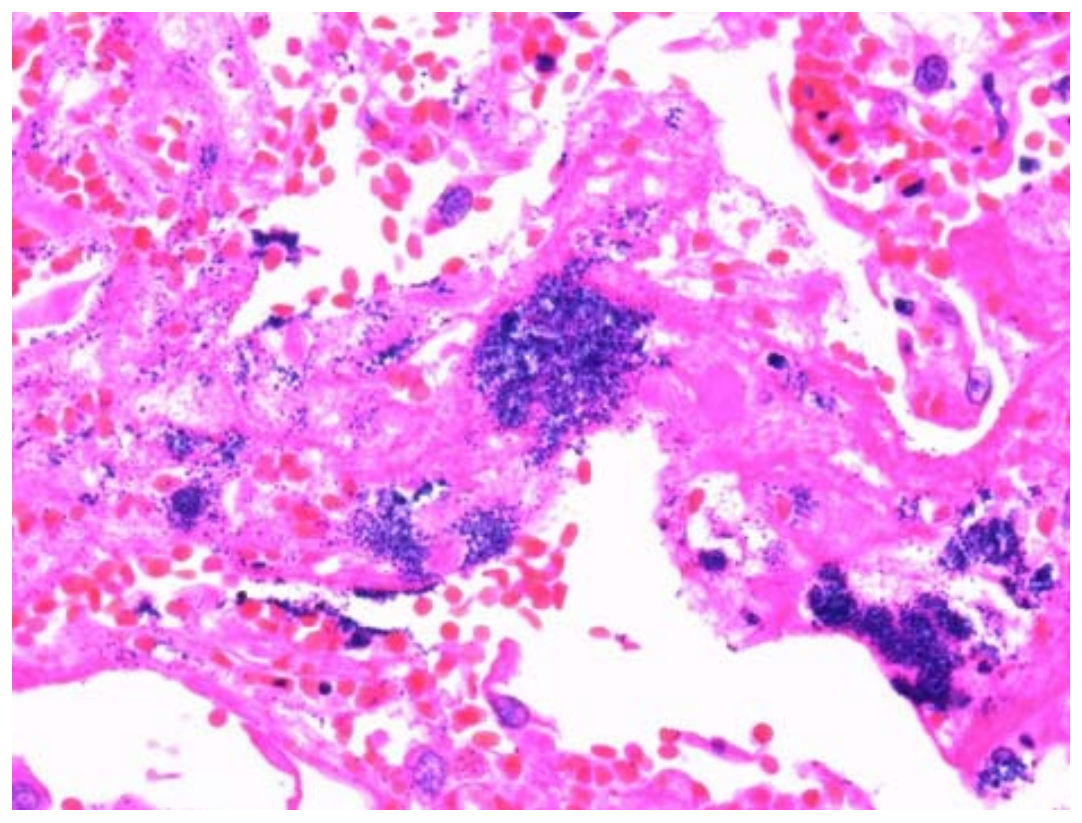


Figure 4

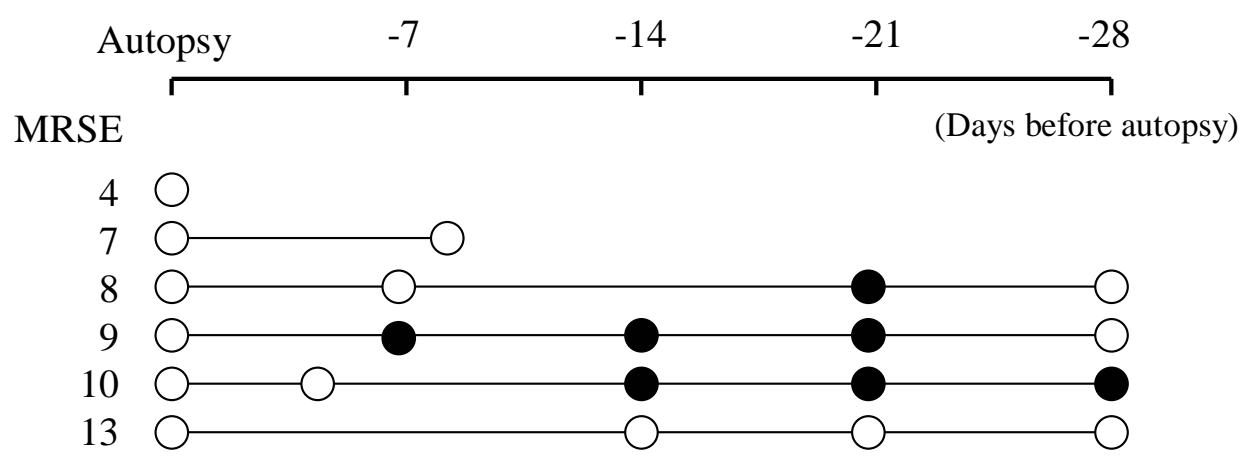

E. faecium

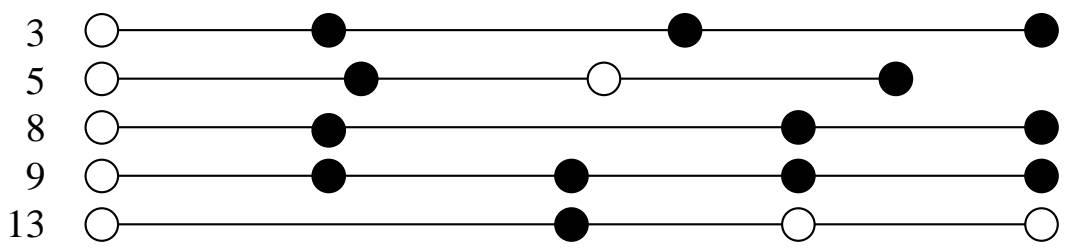

